\title{
Seguro do Capital Social
}

\section{Pedro Koscky Rosa}

A instituição do Seguto do capital social, visando garantir os investimentos em compras de ações, é tese que por certo motivará debates, face às controvérsias que provoca, - haja vista aos incontáveis beneficios da medida proposta, em oposição aos argumentos desfauoráveis.

Tratando-se de medida eminentemente técnica, há necessidade de estudos detalhados, quer sob o aspecto econométrico, atuarial, estatistico, quer sob - legal, juridico e outros, que venham propiciar elementos concretos para definir e alinhar vantagens e desvantagens; conveniências e inconveniências, na implantação do seguro.

A presente proposição devidamente analisada e equacionada, poderá propiciar, no interêsse do desenvolvimento das emprêsas, uma maior segurança na evolução dos investimentos em compras de ações.

MERCADO de capitais no Brasil tem sido caracterizado por uma certa inquietação por parte dos tomadores de ações, que, receosos de falências, concordatas, inflação galopante, possibilidades de "cracks" e "booms", etc., não conservam ações adquiridas como reserva de valores (poupança acumulada) - na exespeculativo.

Essa atitude do tomador de ações é assaz perceptivel quando se trata de conjuntura desfavorável para o mercado de capitais abalos politicos; modificação da politica crediticia e/ou de salários; problemas de "stocks": retenção voluntária especulativa, escassez real de mercadorias, etc. - quando então o proprietário de ações procura desvencilhar-se das mesmas a qualquer preço, inclusive com prejuizo de parte do próprio capital que investiu na sua compra, isso sem mencionar os deságios e quedas gerais 
de valores que habitualmente ocorrem quando transparece inquietação sôbre a evolução dos negócios.

Se houvesse um instituto segurador das ações vendidas na Bolsa, é de se presumir que o tomador de ações vendo parantido seu capital contra possíveis desastres econômicos, tendesse a canalizar sua poupança, seu capital livre, para novas compras de ações, conservando-as como reserva de valores e fontes de rendimentos mais ou menos fixos e regulares (dividendos). Caso o instituto segurador das ações ganhasse vulto, essa conduta do tomador de ações, generalizando -se, conduziria a uma situação concreta de maior permeabilidade à estabilização econômica, ao nivel geral dos negócios, com implicações conjunturais e estruturais. A repercussão geral do instituto segurador das ações seria do mais elevado conteúdo positivo, do ponto-de-vista psicológico, mòrmente no que se refere ao comportamento do tomador de ações. Tal repercussão fundamentar-se-ia na possibilidade efetiva, que proporcionaria o nôvo instituto segurador, seja na expansão do mercado de valores (maior colocação de ações na Bolsa). seja como mecanismo auxiliar de corretivo à especulação.

Essas duas consequiências do seguro do capital social vericar-se-iam pelas novas condições que seriam impostas à taxa de juro, com redução do encaixe de entesouramento, e maior canalização de capitais disponiveis na comunidade para a preferência pela liquidez no motivo de transações e no de precaução, restringindo-se a um minimo a absorção de capitais no motivo de especulação, para utilizar a terminologia keynesiana.

As novas condições a serem incutidas na sistemática vigente da taxa de juro, traduziriam, pelo menos, uma certeza maior quanto ao seu comportamento e evolução no futuro, que inevità velmente possuiriam maior estabilidade.

Ora, se o seguro do capital social visa precipuamente restringir e submeter a um contrôle estatisticamente verificável, o encaixe liquido vinculado à especulação, é de se esperar a estabilização a curto e longo prazo da taxa de juro, porque "é, sobretudo, pelo encaixe de especulação e a preferência pela liquidez que se vai fazer a determinação da taxa de juro, pois que êsse encaixe é o que está, por excelência, sujeito às variações. E' por êle que se vai traduzir, principalmente, a ação da procura e sôbre êle que vai recair a ação da oferta de moeda". (1)

A fim de que seja localizada, do ponto-de-vista da teoria econômica, a influência do seguro do capital social, transcrevemos abaixo trechos do livro Teoria Econômica e Impulso Keynesiano, de Alain Barrère, que esclarecem o mecanismo da taxa de juro, do encaixe de especulação e a preferência pela liquidez, que cons- 
tituem os fatos e os fenômenos econômico-monetários que sentirão mais perceptivamente os efeitos estabilizadores do nôvo instituto segurador:

"Sabemos que KEYNES estabelece como principio que a preferência pela liquidez, que se traduz por uma procura de moeda, é dependente, antes de tudo, da incerteza relativa às futuras taxas de juro". Se não houvesse incerteza, se conhecêssemos o futuro com bastante probabilidade, as taxas atuais de juro poderiam adaptar-se sem dificuldade aos valores futuros. Em conseqüência, os detentores de moeda teriam sempre vantagem em emprestar sua liquidez, pois, estando seus cálculos isentos de imprecisão, não teriam de se precaver contra eventuais enganos (não aludimos aos riscos previsiveis cobertos pelo encaixe de precaução, mas ao risco econômico, que resulta das variações dos valores e dos preços). Assim, teriam mais vantagem em emprestar seu dinheiro a juro, do que em conservá-lo estéril. Esta hipótese é a que serve de base à explicação clássica que faz, em conseqüiência, abstração do encaixe de especulação que, para ela,
não tem objetivo.

O detentor de moeda utiliza, portanto, seu encaixe de especulação para gozar das conseqüências da incerteza concernente ao futuro. Uma vez sendo a taxa de juro, para êle, que o recompensa do abandôno da liquidez, a medida em que concordará em se desfazer dela dependerá de suas previsões relativas às taxas de juro futuras. Ora, de acôrdo com o que se disse sôbre o desconhecimento do futuro, não se podem conhecer essas taxas com precisão; em particular, não se pode saber com certeza qual será a taxa de juro corrente num número de anos $\mathrm{N} e$, portanto, qual será o valor de um crédito qualquer nessa época. Se o detentor de moeda adquire êsse crédito e tem, antes de seu ven cimento, necessidade de dinheiro, que o obriga a vendê-lo para voltar à sua liquidez, pode sofrer uma perda.

No mercado de crédito, a incerteza quanto às taxas futuras de juros é objeto de apreciação pessoal; mas a opinião dominante se forma e sobressai pela cotação dos títulos no mercado. Todo detentor de moeda, tendo opinião diferente da comum, tenderá a conservar suas disponibilidades, e, portanto, a aumentar seu encaixe de especulação, para tirar proveito das modificações antecipadas no nivel das cotações. Resulta dai que as previsões relativas às taxas futuras de juro agem de maneira direta sôbre a preferência pela liquidez, conseqüentemente, sôbre a procura de moeda, e, por conseguinte, sôbre a taxa atual do juro.

Tal fato é passivel de exprimir-se de modo ligeiramente diferente, levando-se em conta, ao mesmo tempo, as frequientes flu- 
tuações da taxa. As cotações do mercado retratam a opinião média a respeito das taxas futuras, e muitas pessoas aceitam as indicações que essas cotações exprimem. Mas, há outras, querendo tirar proveito do que julgam ser melhor conhecimento do futuro e tomam posição diferente, na alta como na baixa, cons tituindo assim uma comtrapartida.

Ao lado de pessoas que manifestam forte preferência pela liquidez, existem outras cuja preferência é fraca.

De qualquer forma, uma das duas tendências predomina. Em função da tendência dominante, os especuladores tomam posição na Bôlsa, fazem variar as cotações dos valores e, por conseguinte, a taxa do juro. O caráter convencional desta é assim ressaltado ao mesmo tempo que suas possibilidades de variação, em conseqüência da opinião variável dos particulares.

Assim, a preferência pela liquidez passa a depender da previsão das taxas futuras: uma previsão de alta provoca o aumento da procura da moeda e tende a fazer subir a taax de juro, pois os detentores de moeda só concordarão em se desfazer de sua liquidez por uma remuneração mais forte, e inversamente. Uma previsão de alta provoca a alta da taxa atual, porque aumenta a procura de moeda e porque a recompensa exigida é maior, pois deve compensar uma esperança de ganho mais elevado.

Há, porém, outros elementos que se juntam a êste. A taxa atual de juro age sôbre a preferência pela liquidez, pois quanto mais a taxa atual fôr baixa, mais terá oportunidade de subir; portanto, maior será o risco de perdas futuras corrido pelo credor. Este pedirá, pois, para abandonar sua liquidez, recom pensa maior. Ainda mais, os gastos de colocação intervêm nas decisões; como são em geral fixos, opõem-se a uma redução muito grande de taxa.

Tôdas essas razões, ligadas, sobretudo, à incerteza em relação à evolução futura da taxa de juro, determinam certa preferência pela liquidez e, por conseguinte, certa procura de moeda da parte dos sujeitos econômicos. Êstes só abandonam, portanto, sua liquidez na medida em que a recompensa a êles oferecida, isto é, a taxa atual, fôr de natureza a compensar, ou, para retomar a expressão de KEYNEs, a acalmar suas inquietações diante da incerteza do futuro".

Um seguro de capitais investidos em compra de ações deveria conduzir a taxa de juro a um ponto ótimo de estabilização, conseqüência de maior certeza quanto à evolução e ao comportamento da preferência pela liquidez no futuro.

Agora, apresentaremos do ponto-de-vista da técnica de seguro, pròpriamente dita, algumas condições que deveriam presidir 
à materialização do seguro do capital, com vistas, especialmente, à nossa estrutura econômico-social.

1) Conceito: Trata-se de uma modalidade de seguro que visa garantir os investimentos em compra de ações preferenciais ou ordinárias, nominativas ou ao portador.

2) Responsabilidades da Cia. de Segutos: A Cia. de Seguros comprometer-se-ia a indenizar os tomadores de ações das emprêsas, na hipótese exclusiva de falências passadas em julgado.

A Cia. de Seguros garantiria o ressarcimento sòmente do capital investido na compra das ações em seu total liquido. Êsse total, para fins de pagamento pela Cia. de Seguros, seria aquêle efetivamente verificado na Bôlsa pela cotação do dia da compra da ação ou ações, e não pelo seu valor ao par ou de outra cotação de outro dia qualquer.

Para o pagamento seria estipulada uma forma parcelada, consoante a porcentagem da última distribuição de dividendos verificada na firma falida, e, naturalmente, após a sentença judicial.

Aqui surge a alternativa de uma variação: caso o segurado optasse pelo pagamento imediato do capital investido, por ocasião da compra das ações, o prêmio de seu seguro deveria ser maior. Naturalmente, que seria de bom alvitre que à forma parcelada de pagamento fôsse acrescida uma cifra correspondente à taxa de juros legal.

3) Potencialidade do Risco do Seguro: Essa nova modalidade de seguro constituir-se-ia num instituto segurador correspondente à própria confiança do público na aquisição de ações.

E' evidente que o caráter seletivo da Cia. de Seguros, sendo tècnicamente muito mais apurado que o do público em geral, o seu risco seria bem menor.

Por outro lado, o seguro das ações de uma emprêsa qualquer tenderia a incrementar o movimento de suas próprias vendas de capital social na Bôlsa, e, por conseguinte, elevar o seu coeficiente de liquidez, ou seja, reduzir sua vulnerabilidade ao colapso financeiro.

A Cia. de Seguros, por seu turno, poderia com os próprios fundos auferidos dessa modalidade de seguros, efetivar financiamentos às emprêsas seguradas, já que a estabilidade das mes- 
mas e o aumento do volume de seus negócios interessaria diretamente à própria Cia. de Seguros.

4) Repercussões financeiras favoráveis para a Cia. de Seguros: Cumpre ser considerado o aspecto da repercussão dêsse tipo de seguros para as outras modalidades seguradoras já existentes. Iso é, a Cia. de Seguros sòmente aceitaria o seguro do capital social quando a emprêsa possuísse seguros contra incêndio para o seu ativo real, de acidentes do trabalho para a mão-de-obra e seguro de vida em grupo para determinados estratos de seu corpo de funcionários (direitos, técnicos, etc.), sendo as indenizações dêsse seguro em grupo reversiveis à própria emprêsa.

Também, caberia observar que o sistema de distribuição do risco "pro-rata" entre outras congêneres, iria diminuir o risco matemático de cada Companhia "per-si". Aliás, conforme o sistema vigente para o setor de ramos elementares, por exemplo. O risco do seguro do capital social, consoante seja o rigoroso critério de seletividade do segurado, corresponderá a um r'sco menor, v. g., que o seguro de transportes. As reservas técnicas, portanto, serão também menores.

5) O prêmio do seguro: Quanto aos prêmios, deve-se acentuar que a sua incidência, "a fortiori", oscilará estatisticamente consoante o tipo de atividade da emprêsa segurada, e deverá ser cobrado em parte da emprêsa e em parte do segurado tomador de ação, ou ações.

Aliás, o tomador de ações poderá optar por aceitar ou recusar o seguro, e, nessa últ ma circunstância, à emprêsa e ao tomador de ações não corresponderá obrigação financeira alguma, pois no caso não existirá seguro.

Entretanto, cada emprêsa segurada deverá pagar um prêmio mínimo para comprar a apólice do seguro do capital. Dest'arte, à cada ação vendida com seguro corresponderá uma entrada de numerário na Cia. de Seguros. Entretanto, para apólices especiais, a própria emprêsa segurada poderia pagar os prêmios do seguro de um certo número de ações "a priori", as quais seriam colocadas no mercado já seguradas.

O estudo da incidência das alíquotas dos prêmios poderia partir de amostragens estatisticas setoriais e inter-setoriais do se- 
guinte tipo, naturalmente depuradas das influências sazonais e regionais:

FALENCIAS E CONCORDATAS ENTRE FIRMAS DOS PRINCIPAIS RAMOS DE ATIVIDADE - RIO DE JANEIRO E SAO PAULO JANEIRO A NOVEMBRO DE 1962.

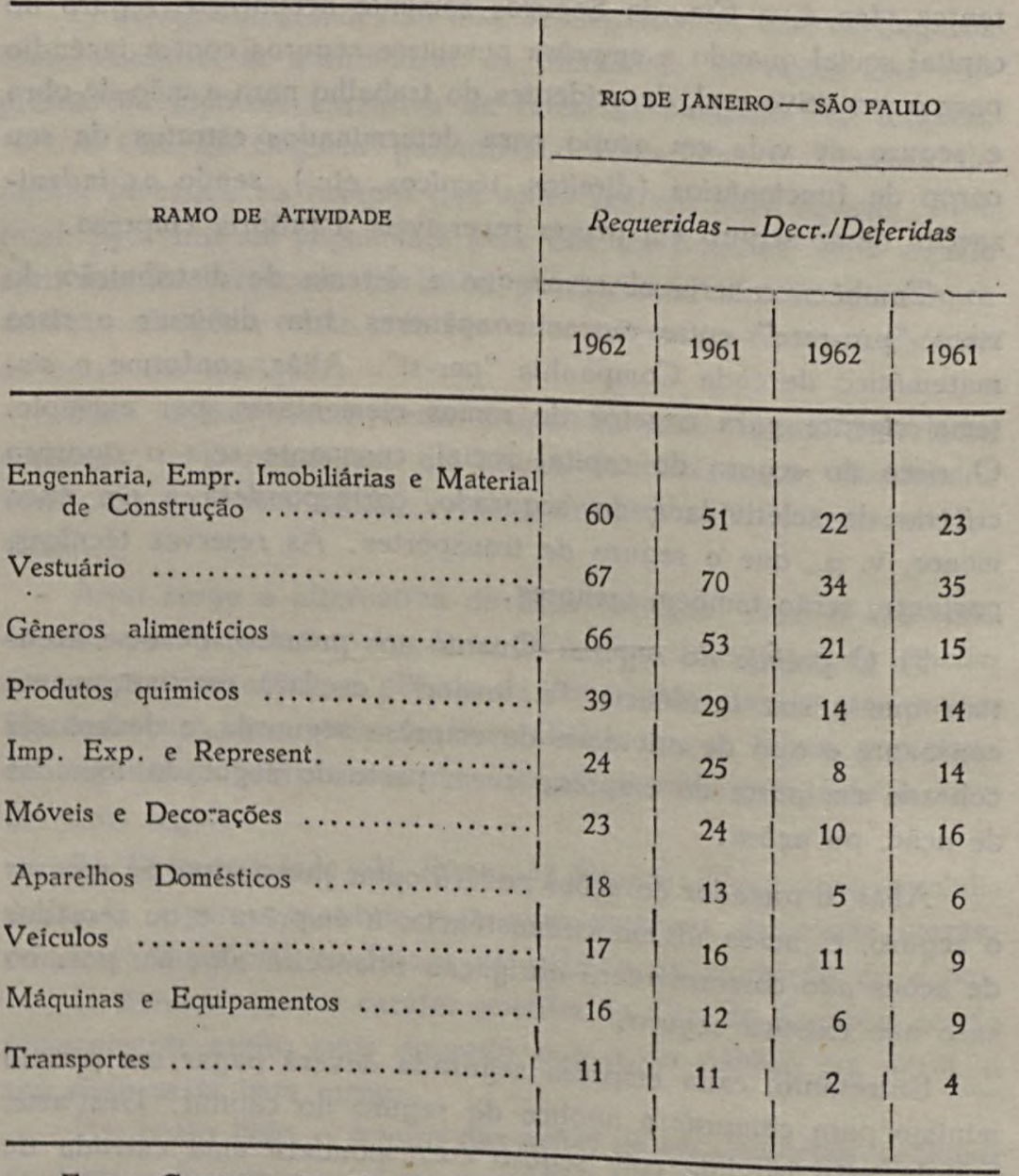

Fonte: Cartórios (In Conjuntura Econômica).

6) A possibilidade do monopólio pelo govêrno do seguto do capital social: Caso o Govêrno chame a si tôda a responsa bilidade do risco do seguro do capital social, dever-se-á amalgamar a recente instituição do Fundo Nacional de Investimentos (F.N.I.) com a nova modalidade de seguro, de tal forma que 
fique garantida a máxima vantagem econômico-social dos investimentos que os recursos do seguro propiciarão (vd. Lei 4.242).

Como os investimentos do F.N.I. deverão localizar-se, principalmente, no setor infra-estrutural da economia, onde o efeito do mult plicador das inversões e da mão-de-obra (Keynes e Kahn) apresentam indices elevados, fica claro que as próprias emprêsas privadas sentir-se-ão mediata ou imediatamente beneficiadas pelo F.N.I., já então com um volume maior de recursos de que o proverá o seguro do capital social.

As companhias de seguros, por outro lado, teriam suas receitas aumentadas mesmo no caso do monopólio estatal do seguro do capital social, pois, como adquirentes obrigatórias de ações do Instituto de Resseguros do Brasil (Decreto-lei $n^{\circ}$ 9.735, de 4-9-46 e Decreto $\mathrm{n}^{\circ}$ 21.810, de 4-9-46), veriam suas ações acrescidas de maiores dividendos que distribuiria aquêle Instituto, face à alta rentabilidade do seguro inovado, que então seria monopolizado plo I.R.B.

Além do mais, é razoável supor que o I.R.B. exigisse que os seus novos segurados (as emprêsas) adotassem outras modalidades de seguro já existentes, como incêndio, seguro de vida em grupo, lucros cessantes, crédito interno, etc., o que novamente iria expandir o movimento de seguros nas sociedades privadas.

No caso de monopolização total do seguro do capital social pelo Estado, o Govêrno deveria ajustar medidas que evitassem conseqüências desfavoráveis no setor privado, que poderia recear o estabelecimento de contrôle estatal rígido sôbre o mercado de ações, conforme, "mutatis mutandis". ocorreu no setor cambial, com as instruções 244 e 245 da SUMOC (24-8-63).

Por outra forma, o Govêrno deveria diligenciar no sentido de suprir a insuficiência de agenciamento do I.R.B., que, ao menos na fase iniical de consolidação do nôvo seguro, poderia delegar a coretores e demais habilitados de emprêsas privadas a colocação do seguro.

Também, o Govêrno poderia adotar uma fórmula de semiestatizacão, semi-mononólio, em que. anroveitando-se a organizacão securitária já existente poder-se-ia reduzir ao minimo a participação particular nos lucros operacionais. que seriam vinculados, em sua parte mais significativa, ao F.N.I.

No caso do semi-monopólio o I.R.B. continuaria agindo como simples ressegurador, evitando-se, dest'arte, a irrupção de novas atividades, pois mesmo estas sendo lucrativas, haveriam os custos de instalação, readaptações organizacionais, etc. E, nessa hipótese 
de simples ressegurador, o I.R.B. utilizaria seu recurso legal de ressegurar o mímino de $20 \%$ do seguro do capital social, elevando, conforme o caso, essa percentagem minima até uma maior responsabilidade no risco total.

7) Dispositivo anti-inflacionário no seguro do capital social: Poderia ser agregado às condições gerais da apólice do seguro do capital social um dispositivo de adaptação às condições inflacionárias do Pais, por exemplo, permitindo que o seguro fôssse reavaliado automàticamente na mesma base da reavaliação do ativo, consoante os indices do Conselho Nacional de Economia. Salta aos olhos o grande efeito publicidade de um tal dispositivo.

8) Conclusões: Existem no País, atualmente, por estimativa a "grosso modo", de 16.000 a 17.000 sociedades anônimas, que tendem a aumentar em cêrca de 1.000 por ano, em média, no próximo quinqüênio. "As operações decorrentes da elevação de capital das sociedades anônimas e da fundação de novas emprêsas no período (1962) alcançaram a importância récorde de 341 bilhões de cruzeiros, ou seja, aproximadamente o dôbro da de 1961, que foi de 178 bilhões" (Conjuntura Econômica - Fevereiro 63 dos negócios. Se se acrescentar a essas informações a expansão privado está bem permeável a umases, concluir-se-á que o setor social, que, nas diversas forma um instituto segurador do capital tatização e 3) semi-estatização propostas: 1) privatização; 2) esadequação com os interêsses disponiveis do mercado nacional privado porque propiciará aumal, conduzindo-os ao investimento sas, e ao invest mento público porque ab vendas de ações nas Bôlde Investimentos, parte, ou co porque absorverá o Fundo Nacional modalidade de seguro.

Naturalmente que o objetivo dêste trabalho foi apenas o de apresentar a idéia do seguro do capital social, para cuja cristalização, entretanto, cumpre realizar estudos de econometria, atuariais, estatíst'cos, jurídicos, etc., que irão propiciar elementos concretos que definam as condições gerais da apólice do nôvo seguro, as aliquotas dos prêmios, as reservas técnicas, etc.

Trata-se de uma medida técnica de precaução econômico. financeira perfeitamente exeqüivel, desde que "estruturada adequadamente. Aliás, para dissipar dúvidas pessimistas, lembramos apenas que "the soundness of a security purchase is determined by future developments and not by past history or statistics. But the future cannot be analyzed; we can seek only to anticipate it intelligently and to prepare for it prudently. Here the past comes in - through the back door, as it were - because 
long experience tells us that investment anticipations, like other business anticipations, cannot be sound or dependable unless they relate themselves to past performance. In measuring past performance we should give consideration to both trends and averages". (Security Analysis, Graham, Dodd, Cottle, Fourth Edition, pág. 3). 